\title{
ERRATUM
}

\section{Investigation of sheet-flow processes based on novel acoustic high-resolution velocity and concentration measurements - ERRATUM}

\section{Thibaud Revil-Baudard, Julien Chauchat, David Hurther and Pierre-Alain Barraud}

doi:10.1017/jfm.2015.23, Published by Cambridge University Press,

12 February 2015

In Revil-Baudard et al. (2015), the email address for correspondence was incorrect. The correct email address should be: thibaud.revil-baudard@legi.grenoble-inp.fr. The publisher apologises to the authors and readers for this error.

\section{REFERENCE}

Revil-Baudard, T., Chauchat, J., Hurther, D. \& Barraud, P.-A. 2015 Investigation of sheetflow processes based on novel acoustic high-resolution velocity and concentration measurements. J. Fluid Mech. 767, 1-30. 
